\title{
Development of Training-Based Spelling Strategies for Female EFL Students: Case Study of a Saudi University
}

\author{
Nasrah Mahmoud Ismaiel ${ }^{1} \&$ AbdulRahman Awadh Al Asmari ${ }^{2}$ \\ ${ }^{1}$ English Language Center, Deanship of Supportive Studies, Taif University, Saudi Arabia \\ ${ }^{2}$ Applied Linguistics, Foreign Languages Department, Faculty of Arts, Taif University, Saudi Arabia \\ Correspondence: Nasrah Mahmoud Ismaiel, English Language Center, Deanship of Supportive Studies, Taif \\ University, Saudi Arabia. E-mail: n.ismaiel@tu.edu.sa
}

$\begin{aligned} & \text { Received: September 14, } 2018 \quad \text { Accepted: October 10, } 2018 \text { Online Published: December 29, } 2018 \\ & \text { doi:10.5539/ijel.v9n1p241 }\end{aligned}$ URL: https://doi.org/10.5539/ijel.v9n1p241

\begin{abstract}
Spelling is a major challenge for EFL learners and students in their process of learning the English language. The aim of this study is to investigate the effectiveness of a training program based on certain spelling strategies to help EFL learners improve their spelling achievement. To do this, the differences between the experimental group and the control group, before and after the treatment, were examined. The participants were university students who were selected from a large sample and divided, and studied, in two experimental and control groups based on a spelling production pre-test. The first aim of this study is to examine whether significant differences occurred in spelling-related language learning strategies and English language spelling post-test between the control and experimental groups. The second aim is to examine whether significant differences exist between the mean scores of pre- and post-test of the English language spelling test and spelling-related language learning strategies. Spelling-related language learning strategies were measured using Kristine F. Anderson's "spelling survey" strategies (1987). The spelling test and the spelling program were both prepared by the researchers. The research was conducted for three months, including the proposed program. Data from pre-post instruments was used to investigate the impact the intervention had on EFL in the development of spelling and the use of spelling strategies to learn English. Data from pre- and post- test instruments showed that there were statistically significant differences between the experimental group and the control group in the post-test spelling test as well as the spelling strategies questionnaire. The implemented treatment resulted in a significant improvement in the spelling skill of the experimental group. The results also revealed statistically significant differences between the pre-test and post-test results for the experimental group in the spelling test and the spelling strategies and also the fact that the experimental group improved in spelling skills after their participation in the program, as can be seen in the post-test. In light of these results, the study proposes a number of procedural recommendations that may contribute to raising awareness regarding the importance of teaching spelling strategies for EFL students.
\end{abstract}

Keywords: spelling strategies, spelling test, intervention, English words spelling, female Saudi EFL students

\section{Introduction}

Since spelling mistakes may lead to problems in understanding the written script, the ability to spell constitutes an important part of the writing process (Khuwaileh \& Al-Shoumali, 2000). According to Allaith \& Joshi (2011), literacy is not evaluated only by the language users' reading and writing accuracy but also through correct word spelling. Al-Jarf (2010) also believes that mastery over spelling is a reflection of the level of education. Furthermore, to become adept at spelling in English, there must be an adequate grasp of the connection between English phonemes and graphemes (Al-Busaidi \& Al-Saqqaf, 2015).

Writing is an essential system for transferring the spoken language into something that can be read and seen. Spelling words correctly is also associated with literacy since literacy is not appraised only based on reading and writing competence. In pedagogical terms, according to Massengill (2006) and Templeton \& Morris (2001), second language (L2) learners would struggle more in their English writing than first language (L1) speakers due to different reasons. AlSaawi (2015) believes that Arab learners of EFL struggle with English spelling more than any other non-native speakers. 
Since conveying the meaning is the foremost goal in languages, spelling is, thus, a basic literacy skill. Due to a longtime lack of awareness regarding this issue, Saudi EFL learners have come to be generally unable to spell or pronounce very simple monosyllabic words, even after years of instruction (Allred, 1984; Crittenden, 2013). Educators tend to focus on what they believe are more important skills such as speaking and reading, thus neglecting the spelling skill. Arab university students also have many problems in their use of English vowels in spelling. The reason for this might be due to the fact that vowels seem to be more irregular than consonants, probably because of the perceptible mismatch between phonemes and graphemes. Language interference, e.g. there are no written vowels in Arabic to precisely stand for those in English, also plays an important role in their difficulty for Arabic speaking learners of English (Haggan, 1991).

The present study aims to address some of the difficulties that Saudi Arabic-speaking students face in their learning of English spelling. It also proposes a training program for spelling strategies for EFL learners to use to overcome these difficulties.

\subsection{Problem Statement}

When attempting to write, students may experience frustration because of the difficulties they may have with punctuation, spelling, and handwriting. According to Holmes \& Malone (2004) and Fender (2008), even many advanced Saudi EFL learners have difficulty remembering specific English spelling patterns. Spelling, in particular in the English language, is a complex language skill important at all levels of education. Some words with completely different meanings, for instance, are pronounced the same, but their spelling is quite different, such as "plane" and "plain". Predictable phonetic variations are sometimes not represented in order to maintain the semantic connection among related words. To exemplify, "courage" and "courageous" are similar in spelling but differ phonetically. Anderson $(1983,1987)$ believes poor spellers tend to continue to use a limited number of strategies which affects their fluency, underlining the need for further linguistic knowledge. They are not, therefore, able to shift to a higher level of spelling strategies which depend on basic levels of linguistic knowledge. Unlike better spellers, they are not able to identify the morphemic and syntactic constraints distinctive of English spelling.

In their research, De La Paz \& Graham (1997) concluded that dictation could reduce difficulties such as poor spelling and result in longer and better-written paragraphs. Many students get relatively lower scores on tests, which might be due to the type of spelling learning strategies they use or they have been trained to use.

The second reason for examining this issue is that teaching spelling is largely absent from university curricula, especially in Saudi Arabian universities. Spelling is taught as much as, or even less than, the middle schools. Traditionally, teaching English at the university level is focused on the four language skills, i.e. reading, writing, listening, and speaking.

The third reason for addressing this issue in the current study is the lack of time in classrooms for teachers to provide appropriate practice on new words. Therefore, equipping students with spelling strategies would help them tackle this problem on their own and, consequently, be able to have access to a larger number of target vocabulary words. Another reason for conducting this research is that there are few empirical studies that address the topic of learning spelling strategies for Arabic speaking EFL learners, especially in Saudi Arabia. Good spelling requires dedication of adequate time and effort aided, and complemented, by learning appropriate strategies and applying them on a regular basis.

\subsection{Research Hypotheses}

The present study has the following hypotheses:

a) There are significant differences in scores between the experimental group and the control group in the post-test of English Language spelling test and spelling strategies. Students in the experimental group are expected to score higher than those in the control group.

b) There are significant differences between the mean scores of the pre- and post-test of the English language spelling test and spelling strategies. The scores of the experimental group are higher in the post-test.

\subsection{The Significance of the Study}

This study aims to develop and improve students' spelling and writing skills. It offers students a variety of strategies to be implemented on the spelling of new words, which can help them write better. The researchers believe this spelling training program can have great benefits for learners. It may help raise EFL learners, EFL educators, and curriculum designers' awareness of spelling strategies. The current study also intends to make teachers wary of their role in teaching EFL spelling and help students develop spelling strategies and methods to 
become good writers and more motivated and independent learners.

\section{Literature Review}

A writing system is how a spoken language is transformed into the written script. According to Langer (2014), spelling is a representation of language. Bazerman (1991) underlines the importance of writing by pointing out that "writing structures our relations with others and organizes our perceptions of the world". Spelling, in particular, is one of the main components of any writing system, however, English spelling is generally complicated for Arab EFL learners. This complication may stem from their native Arabic language which is a whole different tradition of language and leads to a struggle with, for instance, double consonant letters, silent letters, the final [e], and vowels in general (Abu-Rabia, 2002).

In the late $60 \mathrm{~s}$ and early $70 \mathrm{~s}$, researchers started to increasingly identify spelling as a skill to develop, rather than something to be merely memorized (Templeton \& Morris, 2000). Casbergue and Plauche's research (2005) confirmed the findings of previous research which underlined teachers' role in helping students apply known letter sounds when spelling words. Spelling is a complex language important at all levels of education. Turbill (2000) considers learning spelling a process that involves visual and auditory processing and should be taught systematically and explicitly. Learning to spell, according to O'Sullivan and Thomas (2007), is "closely related to [children's] understandings of how the spoken language is written down, and thus to their learning to read." The most effective way to master English spelling is through phonological skills such as segmenting spoken words into individual phonemes and determining how these phonemes relate to appropriate graphemes (Bradley \& Bryant, 1983, Byrne \& Fielding-Barnsley, 1989; Caravolas, Hulme, \& Snowling, 2001; Snowling, 1980). Missing letters, letter clues, spelling the word by pictures, mixed up letters, and highlighted words and syllables are other examples of spelling strategies (Rashid, Yousuf, \& Imran, 2012). Some researchers believe that learners' performance in reading and spelling influence each other over the distinct stages of literacy development and the direction of this influence changes over time. In their research, Ehri (1997) and Snowling (2000) found that spelling and reading enhance one another in a synergistic way, which means accurate spelling promotes accurate reading and vice versa. Moreover, it should be taken into consideration that different writing systems have different and unique linguistic characteristics that affect the acquisition of literacy skills in different languages (Abu-Rabia, 1997, 2001, 2002).

Spelling is crucial to students' reading and writing success because "spelling errors make a text more difficult to read" (Graham, Morphy, Harris, Fink-Chorzempa, Saddler, Moran, \& Mason, 2008). Comprehension could greatly be influenced by wrong spelling, especially in professional settings where conveying the message is important or when students depend on it for communication. For Gentry (2004), students' fluency in reading and writing and their capacity to become articulate speakers depend largely on correct spelling. There are also several studies, Hart (1969), Jackson (1981), Fender (2008), that address and discuss the challenges that $\mathrm{EFL} / \mathrm{ESL}$ learners from different linguistic backgrounds face in spelling and pronunciation.

In Ormrod and Jenkins' study (1989), which took into consideration the age of participants, children were shown to be able to successfully learn the spellings of over five of the ten words while adults learned the spellings of over six words. To evaluate the effectiveness of the strategy, the authors compared the amount of time an individual spent using each strategy with the number of words they spelled correctly after the study period. They concluded that no specific strategy contributed to the children's spelling, and as for the adults, letter rehearsal proved to be actually detrimental to spelling and only over-pronunciation was an effective strategy. Children's ability to learn to spell must be clearly due to factors and conditions that might be difficult for adults to acquire. This could impede learning, especially when we take into account that $66 \%$ of the previously incorrect spellings were actually mastered.

Al Farsi (2009) studied the effectiveness of using spelling e-games for the spelling performance of fifth-grade female learners and their attitudes towards using e-games in learning English spelling. The findings of the study revealed that using games as a method to learn to spell would facilitate their learning of spelling and improve their attitude towards learning.

It is highly recommended to teach and extensively practice the writing system, in general, and spelling errors, in particular, in classroom settings. Reason and Boote (1994) call for the development of spelling strategies that focus more on learning spelling explicitly and on teaching strategies to learners rather than leaving spelling to be caught incidentally. Learners then become more likely to acquire a repository of spelling strategies that would help imprint new words into their long-term memory bank. 


\subsection{Spelling Learning Strategies}

Al Otaiba and Hosp (2010) and Perfetti (1997) define spelling as "a linguistic skill that involves 'encoding' linguistic forms into written form" in which "[t]he linguistic units-phonological strings, morphemes, and words are provided by the spoken language." Spelling accuracy is a very basic and essential skill and an important and established part of the curriculum (Allred, 1984). In other words, spelling is the interpretation of the speech sound (phoneme) into writing (grapheme). Coulmas (1996) considers spelling an element of orthography and believes highly standardized spelling is a prescriptive element. Macline (2001), on the other hand, contends that spelling is a skill learned and mastered by continual repetition.

Spelling learning strategies are methods or actions learners use when encountering new words. Holmes and Malone (2004) identified four spelling strategies: (a) letter rehearsal, (b) over-pronunciation, (c) comparison of the remembered and the correct spelling, and (d) morphological analysis and visualization.

Several models of spelling strategies have been proposed in previous research. Holmes and Malone (2004), for instance, observed a number of spelling strategies including letter rehearsal, over-pronunciation, comparison of the remembered and correct spelling, and morphological analysis and visualization. They found that these strategies produced good learning success for better spellers but weaker spellers had less success with over-pronunciation, comparison, and morphological analysis. Dobie (1986) emphasized the importance of phonological knowledge and learning techniques that involve the auditory sense. She considered it an inappropriate approach for poor spellers, who typically tended to rely too much on "how words sound". She proposed using phonics and dictation activities with nonsense words so as to train students to learn that they can "depend on their ears to some degree". Anderson (1987) mentioned different strategies effective spellers use including the sound, rules, analogies, words related in meaning or structure, dictionaries, visual information, and error classification scheme.

For Gentry (1997), spelling does not necessarily, and exclusively, mean memorizing the spelling of words. It rather requires an understanding of phoneme-grapheme relationships, morphemic relationships, and the semantic and syntactic influences upon words. In his research, Wilde (1992) noticed that children usually began to use words they often saw in their reading and writing and reading seemed to work to reinforce each other. Mustafa (1997) points out that sounding out is not the right way to teach spelling to children. On the other hand, he suggests steering students' visual memory by asking them questions such as "Can you remember what it looks like? Can you remember seeing that word somewhere? Etc." Gentry (1997) argues that the ability to visualize words is an indicator of a skilled speller. Nelson (1990) also discovered that early phonics instruction stimulated children's development of correct short vowel spelling (cited in Cunningham \& Cunningham, 1992). To evaluate strategy effectiveness, Ormrod and Jenkins (1989) correlated the amount of time an individual spent using each strategy with the number of words they spelled correctly after the study period.

\section{Method}

\subsection{Study Sample}

\subsubsection{Pilot Study}

To examine the validity and reliability of the instruments of the study, and determine the amount of time needed to complete the questionnaires, ninety-three students were randomly selected from a first level batch of EFL students of different non-English majors. All of them were female Saudi students. They completed the spelling survey strategies questionnaire and the spelling test. Their age ranged from 18-24, $(\mathrm{M}=19.034, \mathrm{SD}=1.334)$. Data were then analyzed to determine the reliability of the instruments.

\subsection{Participants}

Ninety three female EFL non-English major students participated in the present study. They studied English for 6 hours per week. The participants were all Saudi and native speakers of Arabic. They were all at beginners' level. The participants were divided into two groups; an experimental group (consisting of 52 students) and a control group (of 38 students). They all had 6 years of EFL instruction in grades 6-12 prior to their admission to Taif University. The experimental group was exposed to the spelling strategies program whereas the control group was not exposed to the program. Before instruction, students in both the experimental group and the control group were pretested by taking the same spelling test and learning spelling survey strategies.

\subsection{Instruments}

\subsubsection{Spelling test}

The spelling test administered in this study contained fifty English words that were prepared by the researchers. 
The words were dictated to the students. Scoring was objective, one point for each correct answer. Scores ranged from 0 to 50 . For the spelling test, the participants took a pre-test in order to identify their preexisting knowledge of spelling.

\section{Psychometric conditions of the spelling test in the current research}

Four items $(1,12,25$, and 40$)$ were deleted based on the item-total correlation, therefore, the test ended up with 46 items instead of 50, suggesting adequate validity. The corrected item-total correlation ranged from 0.25 to $0.66(\mathrm{p}<0.01)$, suggesting adequate item validity as well. The internal consistency was high for the whole test $(\alpha=0.92)$ and split half $(0.95)$. The mean total score was $16.624(\mathrm{SD}=9.988)$.

Table 1. Item total correlation for the spelling test

\begin{tabular}{llllllllll}
\hline $\mathrm{N}$ & $\mathrm{R}$ & $\mathrm{N}$ & $\mathrm{R}$ & $\mathrm{N}$ & $\mathrm{R}$ & $\mathrm{N}$ & $\mathrm{R}$ & $\mathrm{N}$ & $\mathrm{r}$ \\
\hline 1 & 0.106 & 11 & $0.481^{* *}$ & 21 & $0.501^{* *}$ & 31 & $0.548^{* *}$ & 41 & $0.513^{* *}$ \\
2 & $0.495^{* *}$ & 12 & 0.153 & 22 & $0.416^{* *}$ & 32 & $0.504^{* *}$ & 42 & $0.252^{*}$ \\
3 & $0.660^{* *}$ & 13 & $0.341^{* *}$ & 23 & $0.567^{* *}$ & 33 & $0.525^{* *}$ & 43 & $0.437^{* *}$ \\
4 & $0.489^{* *}$ & 14 & $0.508^{* *}$ & 24 & $0.454^{* *}$ & 34 & $0.524^{* *}$ & 44 & $0.475^{* *}$ \\
5 & $0.420^{* *}$ & 15 & $0.503^{* *}$ & 25 & 0.188 & 35 & $0.433^{* *}$ & 45 & $0.446^{* *}$ \\
6 & $0.492^{* *}$ & 16 & $0.363^{* *}$ & 26 & $0.484^{* *}$ & 36 & $0.490^{* *}$ & 46 & $0.507^{* *}$ \\
7 & $0.415^{* *}$ & 17 & $0.479^{* *}$ & 27 & $0.499^{* *}$ & 37 & $0.4433^{* *}$ & 47 & $0.593^{* *}$ \\
8 & $0.552^{* *}$ & 18 & $0.362^{* *}$ & 28 & $0.430^{* *}$ & 38 & $0.297^{* *}$ & 48 & $0.382^{* *}$ \\
9 & $0.510^{* *}$ & 19 & $0.507^{* *}$ & 29 & $0.234^{*}$ & 39 & $0.470^{* *}$ & 49 & $0.529^{* *}$ \\
10 & $0.501^{* *}$ & 20 & $0.451^{* *}$ & 30 & $0.388^{* *}$ & 40 & 0.190 & 50 & $0.516^{* *}$ \\
\hline
\end{tabular}

Table 1 shows that all of the items had significant correlations except for the four items $(1,12,25$, and 40$)$ that had been deleted. Also, the spelling test used in the current study seems to have a good validity.

\subsubsection{Spelling Strategies Survey (SSS)}

In this study, Anderson`s survey (1987) was used to help students scrutinize their strategies and errors and be able to develop a sense of linguistic awareness. The survey instrument included ten spelling strategies. The first five items focused on different strategies used by effective spellers, i.e. the sound, rules, analogies or words related in meaning or structure, the dictionary, and visual information. The sixth and seventh questions focused on proofreading and/or self-correcting strategies used during the editing stage. The rest of the questions focused on an error classification scheme that included seven general categories of words that often prove problematic for basic writers: 1 . words with silent letters, 2. words with unstressed vowels or schwas (g), 3. words with prefixes, 4. words with Latin or Greek roots, 5. words with suffixes, 6. homonym forms, 7. common words and phrases, including transitions.

After the respondents completed the survey, instructors could plan appropriate activities and instruction based on the strategies that were dominant in their methods and error patterns. To illustrate, students who regularly misspelled words with silent letters and unstressed vowels were probably trying to spell words according to the way they sound. Like young writers who rely on sound/letter correspondences, their strategies were confined to surface level information. They were not aware of the morphological principles and underlying patterns inherent in the writing system.

\section{Psychometric conditions of the spelling strategies in current research}

The corrected item-total correlation ranged from 0.24 to $0.63(\mathrm{p}<0.01)$, suggesting adequate item validity. The internal consistency was high for the total questionnaire $(\alpha=0.71)$. The mean total score was $45.720(\mathrm{SD}=$ 6.575).

Table 2. Item-total correlations for spelling survey strategies

\begin{tabular}{llll}
\hline Item No. & $\mathrm{R}$ & Item No. & $\mathrm{r}$ \\
\hline 1 & $0.312^{* *}$ & 9 & $0.361^{* *}$ \\
2 & $0.236^{*}$ & 10 & $0.397^{* *}$ \\
3 & $0.338^{* *}$ & 11 & $0.452^{* *}$ \\
4 & $0.356^{* *}$ & 12 & $0.638^{* *}$ \\
5 & $0.217^{*}$ & 13 & $0.580^{* *}$ \\
6 & $0.415^{* *}$ & 14 & $0.534^{* *}$ \\
7 & $0.387^{* *}$ & 15 & $0.578^{* *}$ \\
8 & $0.503^{* *}$ & 16 & $0.249^{*}$ \\
& & 17 & $0.249^{*}$ \\
\hline
\end{tabular}


Table 2 demonstrates that all of the items had strong positive correlations, indicating the adequate validity of the questionnaire.

Table 3. Descriptive statistics spelling survey strategies questionnaire

\begin{tabular}{llll}
\hline Spelling Survey Strategies Questionnaire & $\mathrm{N}$ & Mean & SD \\
\hline Sound & 93 & 3.430 & 0.632 \\
Rules & 93 & 3.054 & 0.913 \\
Analogies & 93 & 2.839 & 1.044 \\
Words related in meaning or structure & 93 & 2.441 & 1.016 \\
The dictionary and visual information & 93 & 2.237 & 1.077 \\
Proofreading & 93 & 3.011 & 0.891 \\
Self-correcting strategies & 93 & 2.817 & 0.920 \\
Error classification scheme & 93 & 2.527 & 0.939 \\
Error classification scheme & 93 & 2.419 & 0.901 \\
Error classification scheme & 93 & 2.441 & 0.902 \\
Silent letters & 93 & 2.903 & 0.979 \\
Words with unstressed vowels or schwas & 93 & 2.796 & 1.027 \\
Words with prefixes & 93 & 2.731 & 1.012 \\
Words with Latin or Greek roots & 93 & 2.731 & 1.044 \\
Words with suffixes & 93 & 2.613 & 1.064 \\
Homonym forms & 93 & 2.667 & 1.136 \\
Common words and phrases, including transitions & 93 & 2.065 & 1.178 \\
Total mean of the spelling strategies & 93 & 2.689 & 0.387 \\
\hline
\end{tabular}

Table 3 shows that the mean scores for all items ranged from 2.065 to 3.441 while the total mean score for all items was $\mathrm{M}=2.689, \mathrm{SD}=0.387$. These results point out to the fact that the EFL learners in this study did not have sufficient awareness of spelling strategies. Intervention training sessions could be held to help them overcome their difficulty in spelling.

\subsection{The Treatment}

Following the first spelling test and prior to the intervening tasks, both control and experimental groups were asked to describe how well they remembered the spellings of some of the words they had previously spelled correctly. They were asked to describe what went through their minds whenever they spelled the word, and what helped them to remember the spelling. The words were displayed one at a time, and no time limit was imposed on how long they took to produce their explanations. The total time for each participant rarely exceeded 30 minutes. The utterances were tape-recorded. The researchers asked the students to take the spelling test and then to read the spelling survey strategies and analyze their spelling mistakes. The participants were also asked questions related to spelling strategies in the questionnaire. Then, the students were given time to respond to the spelling survey. Finally, the spelling test and spelling strategies survey post-test were administered to both groups the same way as the pre-test. The program was evaluated through the pre-tests and the post-tests and the scores of the experimental group and the control group were compared.

\subsection{Data Analysis Procedures}

Data collection was conducted in the first semester of the academic year 2017/2018. To examine the effectiveness of spelling learning strategies program to develop and improve students' English spelling, the t-test was used. The spelling learning strategies program was the independent variable and the spelling test items were dependent variables. In order to analyze the data, the SPSS 10.00 software was used. First, students' responses in the descriptive statistics of the questionnaire were organized and summarized, including mean and standard deviations to indicate students' use of rote spelling learning strategies. Then, students' scores in the vocabulary test were analyzed and the mean and standard deviations were calculated. Finally, the $t$-test correlation coefficient analysis was implemented to see whether any significant difference existed between the experimental and control groups regarding their spelling learning strategy use. 


\section{Results}

Table 4. A comparison between the experimental and the control groups in pre-tests

\begin{tabular}{llllllll}
\hline Research variables & Group & $\mathrm{N}$ & Mean & SD & t & df & Sig. \\
\hline Spelling strategies total score & Experimental & 52 & 46.808 & 5.712 & 1.035 & 88 & 0.304 \\
& Control & 38 & 45.211 & 8.915 & & & \\
Spelling test total score & Experimental & 52 & 15.365 & 10.275 & 0.894 & 88 & 0.374 \\
& Control & 38 & 17.237 & 9.137 & & & \\
\hline
\end{tabular}

Data analysis shows that there are no differences between the experimental and the control groups in the pre-tests of spelling strategies and the spelling test. This means that both groups are homogenous (Table 4).

Table 5. Differences between the experimental and control groups on the spelling strategies, spelling test, and post-tests

\begin{tabular}{llllllll}
\hline Research variables & Group & N & Mean & S.D & T & df & Sig. \\
Spelling strategies total score & Experimental & 52 & 44.365 & 6.438 & 4.920 & 88 & 0.001 \\
& Control & 38 & 36.947 & 7.846 & & & \\
Spelling test total score & Experimental & 52 & 27.212 & 11.770 & 3.430 & 88 & 0.001 \\
& Control & 38 & 18.763 & 11.216 & & & \\
\hline
\end{tabular}

Data analysis showed that there were significant differences between the experimental group and the control group in spelling strategies and in the spelling post-tests, which goes on to confirm the first hypothesis of the present study. In other words, the mean of the experimental group was higher than that of the control group in the spelling strategies with a $\boldsymbol{t}$ value $=4.920, \mathrm{p}<0.01$. The researchers attribute the positive results obtained by the experimental group to the effectiveness of the administered program which included a lot of spelling activities, proportionate to the students' level, that the students shared with each other (see Table 5 above).

Table 6. Mean and standard deviation for the pre- and post-tests of spelling strategies and the English language spelling test for the experimental group

\begin{tabular}{llllllll}
\hline Research variables & Mean & $\mathrm{N}$ & $\mathrm{Sd}$. & Paired differences mean & $\mathrm{t}$ & $\mathrm{df}$ & Sig. \\
\hline Post-test of Spelling strategies & 44.365 & 52 & 6.438 & \multirow{2}{*}{2.442} & 2.235 & \multirow{2}{*}{51} & 0.030 \\
Pre-test of Spelling strategies & 46.808 & 52 & 5.712 & & & & \\
Post-test of Spelling test & 27.212 & 52 & 11.769 & \multirow{2}{*}{0.846} & 51 & 0.000 \\
Pre-test of Spelling & 15.365 & 52 & 10.275 & & & \\
\hline
\end{tabular}

In Table 6, the results showed that the differences between the mean scores of the pre- and post-tests of spelling strategies were in favor of the post-test $\boldsymbol{t}(51)=2.235, \mathrm{p}<0.05)$, and for the spelling test, $\boldsymbol{t}(51)=11.846, \mathrm{p}<$ 0.01 ). These differences underline the importance of the spelling program and its related training and show the importance of the teaching style and additional materials that the researchers administered during the program.

\section{Discussion and Conclusions}

The main goal of the present study was to investigate the effectiveness of a program based on spelling strategies to develop the spelling skill of female Saudi EFL university students. Its findings revealed that the administered spelling strategies were an effective means to improve students' spelling skills. This was further confirmed by the descriptive and the frequency analysis gathered from weekly achievement test sessions that the experimental group took. The analysis results of the experimental and control group showed that students in the experimental group not only had better and improved performance compared to students in the control group but their performance also improved at a higher pace than that of the students in the control group.

The results of the present study showed statistically significant differences between the mean scores of the experimental group and the control group in each of the pre- and post-test mean scores, in favor of the experimental group. This finding is in accordance with the findings of other studies (Al Farsi, 2009; Bradley \& Bryant, 1983, Byrne \& Fielding-Barnsley, 1989; Caravolas, Hulme \& Snowling, 2001; Nahari \& Alfadda, 2016; Snowling, 1980) which confirmed our hypothesis that spelling strategies contribute to spelling learning in EFL/ 
ESL.

As for the second hypothesis of the study, i.e. the existence of significant differences between the mean scores of the pre- and post-test of the English language spelling test and spelling strategies, there were statistically significant differences in the total mean score of the post-test between the experimental group and the control group, in favor of the experimental group. The statistical analysis of the data gathered during the monitoring of the experimental and control group revealed that the mean score of the experimental group was higher (27.212) than the control group (18.763). On average, students in the experimental group scored higher than the students in the control group. These results can be attributed to the positive role spelling strategies played in helping EFL learners in dictating and/or writing in English (Al Hart, 1969; Jackson, 1981; Gentry, 2004; Fender, 2008; Bulushi \& Al Seyabi, 2016). The findings of the present study revealed that using a spelling strategy could help learners, especially less competent spellers, overcome the challenges they might face in writing or dictating in a foreign language. This was further confirmed by the descriptive and the frequency analysis gathered from preand post-tests that both groups performed. In addition, spelling skills are proved to affect positively learners' reading comprehension and in general their English achievement. This is in accordance with Adams-Gordon's research (2010) which found that the test-study-test plan, or experimental studies, were the most effective tools to help students reach spelling learning objectives.

The findings of this study add and contribute to the previous research on spelling. However, it should be taken into consideration that Arabic and English are two largely different language systems. For Haggan (1991), studying native Arabic speakers who learn English is interesting for two reasons: first, English and Arabic have entirely different writing systems; second, spelling in Arabic is quite regular and is done according to the pronunciation of the word while English spelling is often irregular. He found that many of the spelling mistakes made by Arabic speaking learners were due to their mispronunciation and their lack of awareness about regular spelling patterns. In the same vein, Bebout (1985) categorized spelling mistakes made by Arabic speaking learners into eight categories: consonant doubling errors, other consonant errors, errors involving the schwa, errors involving silent [e], other vowel errors, letter mis-ordering, unanalyzables, and homophones.

The results of this study have several implications for EFL instruction in universities. First, EFL teachers are advised to provide their learners with spelling strategy training which can lead to better achievement in spelling, vocabulary, and writing. In other words, if EFL learners are made aware of what is involved in the spelling process and what is necessary to write correctly, then it is possible for them to take steps to meet the demands of the spelling situation. Second, EFL learners are encouraged to become more conscious of their own strategy use. These strategies can be purposefully taught and learned as powerful spelling-enhancement tools. Finally, the researchers suggest future research should focus on investigating the effectiveness of spelling strategy programs for primary, middle, and high school students.

\section{References}

Abu-Rabia, S. (1997). Reading in Arabic orthography: The effect of vowels and context on reading accuracy of poor and skilled native Arabic readers in reading paragraphs, sentences, and isolated words. Journal of Psycholinguistic Research, 26, 465-482.

Abu-Rabia, S. (2000). Effects of Exposure to Literary Arabic on Reading Comprehension in a Diglossic Situation. Reading and Writing: An Interdisciplinary Journal, 13, 147-157.

Abu-Rabia, S. (2001). The role of vowels in reading Semitic scripts: Data from Arabic and Hebrew. Reading and Writing: An Interdisciplinary Journal, 14, 39-59.

Al Bulushi, M., \& Al Seyabi, F. (2016). Spelling Strategies of Omani EFL Students. English Linguistics Research, 5(3), 1-14.

Al Farsi, R. (2009). The effect of spelling E-games on 5th grade EFL learner's spelling performance and attitudes. (Unpublished master's thesis, Sultan Qaboos University, Muscat, Oman).

Al Otaiba, S., \& Hosp, J. L. (2010). Spell it out: The need for detailed spelling assessment to inform instruction. Assessment for Effective Intervention, 36, 3-6.

Al-Busaidi, S., \& Al-Saqqaf, A. H. (2015). English Spelling Errors Made by Arabic-Speaking Students. English Language Teaching, 8(7), 4742-4750.

Al-Jarf, R. (2010). Spelling error corpora in EFL. Sino-US English Teaching, 7(1), 6-15.

Aljelajel, K. M. (2006). Invented Spelling in Arabic: What Do United Arab Emirates. Phd Thesis, Department of Language, Reading And Culture (U.A.E) Sixth Grade Students Know About Arabic Spelling, The 
University Of Arizona.

Allaith, Z. A., \& Joshi, R. M. (2011). Spelling performance of English consonants among students whose first language is Arabic. Reading and Writing, 24(9), 1089-1110.

Allred, R. (1984). Comparison of proofreading-type standardized spelling tests and written spelling test scores. Journal of Educational Research, 77, 298-303.

Alsaawi, A. (2015). Spelling Errors Made by Arab Learners of English. International Journal of Linguistics, 7(5), 1948-5425.

Anderson, K. (1983). The Spelling Errors and Strategies of College and Adult Spellers.” Innovative Learning Strategies 1983-1984. Commerce, TX: College Reading Improvement Special Interest Group, International Reading Association.

Anderson, K. (1987). An Analysis of the Spelling Errors Made by Three College Students in Essay Writing. Journal of Research and Development in Education, 20, 40-50.

Bazerman, C., \& Paradis, J. G. (1991). Textual dynamics of the professions: Historical and contemporary studies of writing in professional communities. University of Wisconsin Press.

Bradley, L., \& Bryant, P. E. (1983). Categorizing sounds and learning to read: A causal connection. Nature, 301, 419-421.

Byrne, B., \& Fielding-Barnsley, R. (1989). Phonemic awareness and letter knowledge in the child's acquisition of the alphabetic principle. Journal of Educational Psychology, 81, 313-321.

Caravolas, M., Hulme, C., \& Snowling, M. J. (2001). The foundations of spelling ability: Evidence from a 3-year longitudinal study. Journal of Memory and Language, 45, 751-774.

Casbergue, R., \& Plauche, M. (2005). Emergent writing: Classroom practices that support young writers' development. In R. Indrisano \& J. Paratore (Eds.), Learning to write writing to learn (pp. 15-16). Newark, DE: International Reading Association.

Coulmas, F. (1996). The Blackwell Encyclopedia of Writing Systems. Oxford: Black wells.

Crittenden, E. M. (2013). The Effectiveness of Two Spelling Approaches on Vocabulary Development for Hispanic Learners. Published by Proquest LLC.

Cunningham, M., \& Cunningham, W. (1992). Making words: Enhancing the invented spelling-decoding connection. The Reading Teacher, 46(2), 106-115.

De La Paz, S., \& Graham, S. (1997). Effects of dictation and advanced planning instruction on the composing of students with writing and learning problems. Journal of Educational Psychology, 89(2), 203-222.

Dobie, A. B. (1986). Orthographical Theory and Practice, or How to Teach Spelling. Journal of Basic Writing, $5(2), 41-48$.

Ehri, L. (1997). Learning to read and learning to spell are one and the same, almost. In C. A. Perfetti, L. Rieben, \& M. Fayol (Eds.), Learning to spell: Research, theory, and practice across languages (pp. 237-269). Mahwah, NJ: Lawrence Erlbaum.

Fender, M. (2008). Spelling knowledge and reading development: Insights from Arab ESL students. Reading in a Foreign Language, 20(1), 19-42.

Gentry, J. R. (2004). The science of Spelling: The Explicit Specifics that Make Great Readers and Writers (and Spellers). Portsmouth, NH: Heinemann.

Gentry, R. (1997). My kid can't spell: Understanding and assisting your child's literacy development. Portsmouth, NH: Heinemann.

Graham, S., Morphy, P., Harris, K., Fink-Chorzempa, B., Saddler, B., Moran, S., \& Mason, L. (2008). Teaching spelling in the primary grades: A national survey of instructional practices and adaptations. American Educational Research Journal, 45, 796-825.

Hart, C. (1969). Some English Pronunciation Difficulties in Malaysia. ELT J., 23, 270-273.

Holmes, V. M., \& Malone, N. (2004). Adult spelling strategies. Reading and Writing: An Interdisciplinary Journal, 17, 537-566.

Jackson, H. (1981). Pronunciation of English Consonants by Indian Learners. ELT J., 35, 418-420. 
Johnston, F. R. (2001). Exploring classroom teachers` spelling practices and beliefs. Reading Research and Instruction, 40(2), 143-156.

Khuwaileh, A. A., \& Al Shoumali, A. (2000). Writing errors: a study of the writing ability of Arab learners of academic English and Arabic at university. Language Culture and Curriculum, 13(2), 174-183.

Langer, N. (2014). Orthography as Social Action: Scripts, Spelling, Identity and Power (Language and Social Processes 3). In A. Jaffe, J. Androutsopoulos, M. Sebba, \& S. Johnson (Eds.), Language Policy (pp. 1-3).

Massengill, D. (2006). Mission accomplished...it's learnable now: Voices of mature challenged spellers using a word study approach. Journal of Adolescent \& Adult Literacy, 49, 420-431.

Mohamed, W., Elbert, T., \& Landerl, K. (2011). The development of reading and spelling abilities in the first 3 years of learning Arabic. Read Writ, 24, 1043-1060.

Moore, D. W., Moore, S. A., Cunningham, P. M., \& Cunningham, J. W. (1994). Developing readers \& writers in the content areas $K-12$ (2nd ed.). New York: Longman.

Mustafa, M. (1997). Beyond traditional phonics. Portsmouth, NH: Heinemann.

Nahari, A. A., \& Alfadda, H. A. (2016). From Memorizing to Visualizing: The Effect of Using Visualization Strategies to Improve Students' Spelling Skills. English Language Teaching, 9(6), 1-18.

O’Sullivan, O., \& Thomas, A. (2007). Understanding spelling. England: Routledge.

Ormrod, J. E., \& Jenkins, L. (1989). Study strategies for learning spelling: correlations with achievement and developmental changes. Perceptual and Motor Skills, 68, 643-650.

Rashid, M., Yousuf, M. I., \& Imran, M. (2012). Strategies for Spelling Improvements. Academic Research International, 3(1), 65-70.

Reason, R., \& Boote, R. (1994). Helping children with reading and spelling: A special needs manual. USA: Routledge. https://dx.doi.org/10.4324/9780203426845

Reason, R., \& Boote, R. (1994). Helping children with reading and spelling: A special needs manual. Routledge: USA. http://dx.doi.org/10.4324/9780203426845

Snowling, M. (2000). Dyslexia: A cognitive developmental perspective (2nd ed.). Cambridge, MA: Basil Blackwell.

Snowling, M. J. (1980). The development of grapheme-phoneme correspondences in normal and dyslexic readers. Journal of Experimental Child Psychology, 29, 294-305.

Templeton, S., \& Morris, D. (2000). Spelling. In M. L. Kamil, P. B. Mosenthal, P. D. Pearson, \& R. Barr (Eds.), Handbook of Reading Research (Vol. III, pp. 525-543). Mahwah, NJ: Lawrence Erlbaum Associates.

Templeton, S., \& Morris, D. (2001). Reconceptualizing spelling development and instruction. Reading Online, 5(3). Retrieved from http://www.readingonline.org/articles/handbook/templeton/index.html

Turbill, J. (2000). Developing a Spelling Conscience. Language Arts, 77(3), 209-17.

Wilde, S. (1992). You kan red this: Spelling and punctuations for whole language classroom, K-6. Portsmouth, NH: Heinemann.

Wilde, S. (1997). What's a schwa sound anyway? A holistic guide to phonetics, phonics, and spelling. Portsmouth, NH: Heinemann.

\section{Copyrights}

Copyright for this article is retained by the author, with first publication rights granted to the journal.

This is an open-access article distributed under the terms and conditions of the Creative Commons Attribution license (http://creativecommons.org/licenses/by/4.0/). 